\title{
DIREITOS HUMANOS: INTEGRAÇÃO E COMPLEMENTAÇÃO DOS DISPOSITIVOS NORMATIVOS DO DIREITO BRASILEIRO
}

\author{
Dorita Ziemann Hasse ${ }^{1}$ \\ Tatiane Cristina Gouveia ${ }^{2}$
}

HASSE, D. Z.; GOUVEIA, T. C. Direitos humanos: integração e complementação dos dispositivos normativos do direito brasileiro. Rev. Ciênc. Juríd. Soc. UNIPAR. Umuarama. v. 17, n. 1, p. 83-103, jan./jun. 2014.

RESUMO: O presente trabalho tem como finalidade apresentar a importância da proteção dos direitos humanos tanto no âmbito interno, como no âmbito internacional; a evolução histórica dos direitos humanos, tendo como escopo fundamental o valor da dignidade pessoa humana como um dos princípios orientadores do ordenamento jurídico que contribuiu para o processo de internacionalização dos direitos humanos. Demonstrar a recepção dada aos direitos humanos pela Constituição Federal de 1988 no qual ensejou no processo de redemocratização do Brasil, rompendo a concepção de soberania estatal absoluta e reconhece a existência de limites ao poder do Estado. Busca-se também, analisar a interação entre o sistema jurídico interno e o direito internacional de direitos humanos juntamente com as inovações trazidas pela Emenda Constitucional n ${ }^{\circ} 45$ de 2004 que iniciou a chamada "Reforma do Poder Judiciário" objetivando esclarecer e produzir maior segurança jurídica, inserindo o $\S 3^{\circ}$, ao artigo $5^{\circ}$ da Constituição da Constituição da República Federativa do Brasil.

PALAVRAS-CHAVE: Direitos humanos; Princípios; Limites; Poder; Segurança jurídica.

\section{INTRODUÇÃO}

Considera-se que para ser titular de direitos humanos basta a simples condição de ser humano, isto é, toda pessoa tem a prerrogativa de ser tratado de maneira digna e de ver respeitado a sua subjetividade por qualquer que seja ente político ou não.

A proposição parece não encontrar silogismo efetivo, ou seja, a conclusão exposta não é tão simplista quanto parece a afirmação. E nesse aparente conflito, do abstrato para o concreto, insurge o Direito Internacional dos Tratados,

DOI: https://doi.org/10.25110/rcjs.v17i1.2014.5356

${ }^{1}$ Mestre em Direito Processual Penal, Professora - UNIPAR (dorita@unipar.br), Endereço: Rua Dr. Camargo, $n^{\circ} 5172$ - Cep 87502-010, Umuarama - PR

${ }^{2}$ Acadêmica do PIC 
sobretudo, os Tratados Internacionais que versem Direitos Humanos.

Observa-se que no trajeto histórico os direitos humanos foram sendo sedimentados não por razões óbvias da condição de ser humano, mas em razão de caráter repressivo em que se defendiam tais direitos. Prova disso encontra-se nos precedentes históricos que atualmente corrobora para conferência de legitimidade ao sistema internacional de proteção dos direitos humanitários, como o Direito Humanitário, limitando a atuação estatal em casos de conflitos armados; a Liga das Nações (pós $1^{a}$ Guerra Mundial), com a função de promoção da paz; e a Organização Internacional do Trabalho (OIT), na proteção dos direitos humanos trabalhistas.

Mas o que realmente tem ser considerado como marco principal da inserção da proteção dos direitos humanos no âmbito internacional foi o pós $2^{\mathrm{a}}$ Guerra Mundial, com a criação da Organização das Nações Unidas (ONU), frente às atrocidades cometidas, em massa, contra o ser humano.

Porém, não bastassem os precedentes e marco teórico acima, o Direito Internacional precisou da utilização de instrumentos para que o reconhecimento das tutelas humanitárias fosse de fato efetiva, tendo, por conseguinte, por meio de tratados internacionais, ampliado o campo de abrangência da proteção dos direitos humanos.

Apesar de grande parcela das Nações aderirem aos Tratados Internacionais de Direitos Humanos, estes por vezes, são recepcionados em alguns ordenamentos jurídicos internos, com certa reserva. Em outros termos, aqueles tratados podem ser internalizados em diferentes patamares em face da Lei Maior interna de cada Signatário.

No Brasil, a situação não se mostra tão díspar, e no presente trabalho, observar-se-á que os tratados de direitos humanos podem apresentar no momento de sua internalização diferentes entendimentos quanto ao patamar jurídico em que serão recebidos. Em que pese as alterações introduzidas no texto Constitucional pela Emenda Constitucional $n^{\circ} 45$ de 2004, existem basicamente quatro posicionamentos, quais sejam, o patamar de lei ordinária, de supralegalidade, de supraconstitucional e por fim a corrente que defende o nível sempre constitucional daqueles tratados, seja com a $\mathrm{EC}^{\circ} \mathrm{45} / 2004$, formal ou com fundamento nos próprios dispositivos constitucionais, um caráter material.

Imperioso repisar que as alterações introduzidas no texto Constitucional, com o objetivo de trazer pacificação de entendimentos, parecem que não conseguiram lograr êxito, como se verá a seguir.

\section{DIREITOS HUMANOS: BREVES CONSIDERAÇÕES HISTÓRICAS}

A racionalidade humana, desde os mais antigos documentos escritos 
de natureza jurídica, demonstra especial interesse com a proteção dos direitos individuais da pessoa humana, perante o Estado. Assim, a civilização egípcia foi a primeira na história da humanidade a preocupar-se em deixar Instruções e Sabedorias com o intuito de assegurar o direito das pessoas e dos bens (GUERRA, 2013).

Os povos da Antiguidade foram gradativamente descobrindo a lei que, inerente à sua natureza, deveria ser organizada e codificada sempre em favor dos direitos do homem. Partindo-se do Código de Hamurabi e o Código de Manu, como sendo as primeiras formas jurídicas, ainda que elementares, saíram em defesa da dignidade e da pessoa humana, ainda que contra sujeitos da sua mesma espécie.

Mas adiante, na Grécia, de forma mais coordenada e organizada, surgem vários estudos sobre a questão da igualdade e da liberdade do homem. É o que assevera Sidney Guerra, quando afirma que "o sistema jurídico da Grécia antiga é uma das principais fontes históricas dos direitos da Europa ocidental" (GUERRA, 2013, p. 460).

A forma filosófica como os gregos pensaram esses direitos foi contemplada, mais adiante, pelo pensamento dos romanos que juridicamente reconheceram a possibilidade de existirem divergências entre o justo e o lícito. Assim, pela vez primeira, foi concebida a existência de três estratos de ordem jurídica, a saber: o direito natural, racional e o perpétuo. $\mathrm{O}$ homem, como indivíduo, natureza e dignidade, que na Antiguidade greco-romana, estava oculto, é revelado pelo Cristianismo.

As garantias fundamentais podem ser sentidas e propagadas de forma mais ampla por meio de influencias religiosas e filosóficas, mostrando-se presente de forma simplificada mediante a pregação da igualdade entre os homens na doutrina de Buda (500 a.C.); seguindo-se pela evolução filosófica já de forma mais elaborada, com apontamento da previsão de participação política dos cidadãos defendida pelos sofistas e estóicos, já por volta de 440 a.C.

Com essa revolução, os direitos da pessoa humana na organização da vida pública (política), dão origem a possibilidade de compreensão da ligação entre o indivíduo e a divindade. Centra-se aqui o homem sendo o seu destino pessoal objeto da principal preocupação, conforme analisa Francisco Cleber Alves quando assevera que "o enfoque antropológico é expressivo e revela grande importância na valorização da dignidade humana" (ALVES, 2001, p. 21), referindo-se a primeira grande escola cristã, da qual Santo Agostinho é o maior representante.

O foco da dignidade humana assenta-se no pensamento da doutrina cristã contribuindo para o desenvolvimento de um efetivo humanismo desde a Idade Antiga até a contemporaneidade (GUERRA, 2013). 
Saltando a Idade Média, período em que a ideia de direitos individuais carecia do sentido de hoje, ou seja, de direitos iguais para todos e que a todos podem ser contrapostos. Na passagem do século XII para o século XIII, efetivamente tem início um movimento em direção à instituição que pudesse limitar o poder absoluto dos governantes, conforme assinala Fábio Konder Comparato, "Não se trata ainda de uma afirmação de direitos inerentes à própria condição humana, mas sim o início do movimento para a instituição de limites ao poder dos governantes, o que representou uma grande novidade histórica" (COMPARATO, 1999, p. 60).

O campo era fértil. Preparava-se uma nova época em que o princípio fundamental seria a liberdade de consciência, consubstanciada no contratualismo de Rousseau e depois na Revolução Francesa, cujo lema Liberdade, Igualdade e Fraternidade, veio desencadear um novo sentimento entre os homens, que até então não havia sido experimentado.

As ações que se seguem serão significativas para o processo de internalização dos direitos humanos, refletindo-se nos dias atuais: o direito humanitário, os direitos humanos e o direito dos refugiados (GUERRA, 2013).

Em que pesem as diferenças existentes na concepção dos direitos do homem, não se pode negar a grandeza e importância histórica de sua evolução, como assevera Fabio Konder Comparato:

O que se conta é a parte mais bela e importante de toda a História: a revelação de todos os seres humanos, apesar das inúmeras diferenças biológicas e culturais que os distinguem entre si, merecem igual respeito, como únicos entes no mundo capazes de amar, descobrir a verdade e criar a beleza. É o reconhecimento universal de que, em razão dessa radical igualdade, ninguém - nenhum indivíduo, gênero, etnia, classe social, grupo religioso ou nação - pode afirmar-se superior aos demais. (COMPARATO, 1999, p. 1).

O caminho é longo, as conquistas paulatinas e concomitantes às instituições jurídicas de defesa da dignidade da pessoa humana contra a violência de seus semelhantes que se afastam da humanidade em nome de conquistas menores que não podem prosperar.

\section{O HOMEM: PESSOA E PERSONALIDADE}

Partindo da análise do homem como animal cívico, segundo Aristóteles na obra A Política, projeta-se a ideia de cidade, polis, como berço da integração de pessoas aldeadas no intuído de preservar aquilo que naturalmente se construiu. 
Toda cidade está na natureza e que o homem é naturalmente feito para a sociedade política. Aquele que, por sua natureza e não por obra do acaso, existisse sem nenhuma pátria, seria um indivíduo detestável, muito acima ou muito abaixo, segundo Homero: um ser sem lar, sem família, sem leis.(ARISTÓTELES, 2000, p. 04).

Daí observar-se que o homem, segundo os filósofos, é um animal social e político distinguindo-se a origem e a forma dessa sociabilidade, donde se conclui que Ubi homo, ibi societas, o que independe do seu grau de desenvolvimento. Depreende-se dessa análise que a sociabilidade, como desejo de participação e convivência e a politicidade, como conjunto de relações próprias da convivência com os demais membros do grupo, não se confunde com a concepção atual destinada a esse termo, ou seja, em relação a atuação congressual (FRANÇA, 1977).

\subsection{A PESSOA HUMANA}

Improcedente é a análise de pessoa humana, como originariamente era concebida, considerando-se o desenvolvimento da sociedade em relação a constitucionalização do Direito Civil e o envolvimento dos direitos fundamentais, em todos os ramos do Direito.

Segundo Miguel Reale, (1999) o conceito de pessoa, como categoria espiritual, como subjetividade, que possui valor em si mesmo, como ser de fins absolutos e que, em consequência, é possuidor de direitos subjetivos ou direitos fundamentais e possui dignidade, surge com o advento do Cristianismo, com a chamada filosofia patrística, depois desenvolvida pelos escolásticos.

No contexto jurídico, o termo pessoa foi inicialmente utilizado no século XVI, apresentando-se ligado ao conceito de capacidade jurídica. É o que analisa Clóvis Bevilaqua, sobre o conceito:

Pessoa natural é o homem considerado sujeito de direito e de obrigações. [...] A sociedade é o meio onde vive o homem; nesse meio ele desenvolve a sua atividade em direções diversas, protegido sempre pela ordem jurídica e, portanto, podendo agir como pessoa (BEVILAQUA, 2007, p. 95).

Em que pesem as diferentes concepções sobre a pessoa natural, interessa em especial neste contexto, o entendimento e a distinção que se faz entre o seu significado vulgar e jurídico. Para o homem médio o conceito de pessoa é o ser humano, o qual se mostra insuficiente para o mundo jurídico, referindo-se a pessoa como ser com personalidade jurídica, aptidão para a titularidade de direito e 
deveres (VILASBOAS, 2012).

\subsection{DIGNIDADE DA PESSOA HUMANA: CONCEITO E CONCEPÇÕES}

Historicamente, tomando para esta análise a terminologia empregada por Miguel Reale, (1996), é possível constatar três concepções de dignidade da pessoa humana: individualismo, transpersonalismo e personalismo.

Em se tratado do individualismo, a referência adequada é a de que cada homem, cuidando dos seus interesses, protege e realiza, indiretamente, os interesses coletivos do que se depreende, de algum modo, os direitos fundamentais inatos e anteriores à criação do Estado.

Referindo-se a transpersonalismo, o entendimento é antagônico na medida em que ao ser realizado o bem coletivo se protegem os interesses individuais. Caso haja conflito entre o bem individual e o bem coletivo, prevalecem os valores coletivos, o que resulta na negação da pessoa humana como valor supremo. (REALE, 1977).

Para distinguir os direitos dos homens dos direitos dos cidadãos, aqueles são os direitos do homem separado do homem e da comunidade (SANTOS, 1999).

O que se denomina personalismo, rejeita tanto o individualismo como o transpersonalismo, negando a possibilidade de a possibilidade de existir harmonia espontânea entre indivíduo e sociedade, entendidos como predomínio do indivíduo sobre o coletivo. Destaca-se nesta teoria, que salienta a integração entre os valores individuais e valores coletivos, a distinção entre indivíduo e pessoa. Se ali se exalta o individualismo, o homem abstrato, típico do liberalismo burguês, aqui se destaca que ele "não é apenas uma parte. Como uma pedra-de-edifício no todo, ele é, não obstante, uma forma do mais alto gênero, uma pessoa em sentido amplo - o que uma unidade coletiva jamais pode ser" (MATA-MACHADO, 1991, p. 142).

Destaca-se a pessoa humana enquanto valor cujo princípio correspondente é absoluto, prevalecendo sempre sobre qualquer outro valor ou princípio. Fica assim estabelecido que a pessoa parte é distinta do indivíduo, parte é um valor e o seu princípio correspondente, parte da dignidade da pessoa humana é absoluto.

\subsection{DIREITOS HUMANOS - CONCEITUAÇÃO}

Literalmente, o conceito de Direitos Humanos significa direitos do homem. Esmiuçando, entende-se que são aqueles direitos fundamentais, inerentes a toda pessoa humana passíveis de resguardar basicamente a dignidade, liberda- 
de, solidariedade, igualdade, justiça e fraternidade, dando garantia à integridade física e psicológica de todo e qualquer ser humano diante da ordem social e econômica em que convive.

Alexandre de Moraes, numa visão mais constitucionalista, prefere a expressão direitos humanos fundamentais como:

[...] O conjunto institucionalizado de direitos e garantias do ser humano que tem por finalidade básica o respeito a dignidade, por meio de sua proteção contra o arbítrio do poder estatal e o estabelecimento de condições mínimas de vida e desenvolvimento da personalidade humana (MORAES, 2002, p. 39).

Não cabe utilizar a expressão direitos humanos como sinônimo de direitos fundamentais uma vez que, estes nascem daqueles, ou seja, os direitos fundamentais são constituídos por regras e princípios, são os direitos do homem posto em um ordenamento jurídico. É o Direito Natural positivado constitucionalmente que freia o poder do Estado possibilitando o desenvolvimento saudável da sociedade no sistema político e econômico da Nação.

No entendimento de Dimitri Dimoulis:

Direitos fundamentais são direitos publico - subjetivos de pessoas (físicas ou jurídicas), contidos em dispositivos constitucionais e, portanto, que encerram caráter normativo supremo do Estado, tendo como finalidade limitar o exercício do poder estatal em face da liberdade individual (DIMOULIUS, 2005, p. 54).

Pode-se afirmar então, que direitos fundamentais são os direitos universais garantidos no ordenamento normativo que limitam o poder estatal e permitem o crescimento físico e psicológico do homem, com liberdade individual, sua raça, crença, sexualidade, opinião política, equilibrando de forma justa o desenvolvimento socioeconômico do País.

Vale salientar, que os direitos humanos exercem a função democratizadora do país, e tem como escopo o princípio da dignidade da pessoa humana. Paulo Bonavides define que, "nenhum princípio é mais valioso para compendiar a unidade material da Constituição que o principio da dignidade da pessoa humana.” (BONAVIDES, 2001, p. 233). Assim, na contemporaneidade, há uma grande preocupação constitucional em assegurar a dignidade da pessoa humana no sistema normativo, isto é, em resguardar valores éticos e garantias fundamentais.

Com isso, a dignidade da pessoa humana, como um princípio norteador do ordenamento jurídico, enseja na universalização dos direitos humanos, que na concepção de Flávia Piovesan "é no princípio da dignidade humana que a 
ordem jurídica encontra o próprio sentido, sendo seu ponto de partida e seu ponto de chegada, para a hermenêutica constitucional contemporânea" (PIOVESAN, 2008, p. 38).

É a partir dessa concepção que os direitos humanos fundamentais passaram a ser vistos de forma mais rigorosa, que assegurados constitucionalmente, limitam o poder do Estado e de suas autoridades, ora consagrando os princípios básicos que regem o Estado Moderno. Numa visão mais democrática, é justamente o poder do povo de outorgar seus direitos a seus representantes, para serem guardiões desses.

\section{A RECEPÇÃO DOS DIREITOS HUMANOS PELA CONSTITUIÇÃO BRASILEIRA DE 1988}

A Constituição Federal de 1988 surge num momento histórico crucial para o Estado brasileiro, qual seja o processo de redemocratização rompendo com o autoritarismo anteriormente vigente, que por meio do militarismo desrespeitava e agredia os direitos individuais dos cidadãos.

A Carta Magna brasileira, ao recepcionar os direitos humanos rompe o "status" autoritário do Estado e atribui maior ênfase aos direitos humanos, incluindo nestes os direitos sociais. Demarca, assim, no âmbito brasileiro a democratização do Estado, ensejando considerável impacto no contexto dos direitos fundamentais.

É o que estabelece o preâmbulo constitucional:

[...] instituir um Estado Democrático de Direito, destinado a assegurar o exercício dos direitos sociais e individuais, a liberdade, a segurança, o bem estar, o desenvolvimento, a igualdade e a justiça, como valores supremos de uma sociedade fraterna, pluralista e sem preconceitos, fundada na harmonia social e comprometida, na ordem interna e internacional $[\ldots]$.

Como se verifica o principal objetivo do Estado Democrático de Direito é a proteção aos direitos individuais, a cidadania, a dignidade da pessoa humana e principalmente o pluralismo político, que garante ao povo ampla participação no destino político do país.

Rompe-se desta forma, a concepção de soberania estatal absoluta e se reconhece a existência de limites ao Estado, o que reforça cada vez mais o processo de flexibilização, com objetivo de priorizar a proteção dos direitos humanos condizentes com as exigências do Estado Democrático de Direito.

Seguindo os estudos de Flávia Piovesan: 
A prevalência dos direitos humanos, como princípio a reger o Brasil no âmbito internacional, não implica apenas o engajamento do País no processo de elaboração de normas vinculadas ao Direito Internacional dos Direitos Humanos, mas sim a busca da plena integração de tais regras na ordem jurídica interna brasileira (PIOVESAN, 2008, p. 40).

Nota-se que a prevalência dos direitos humanos é o principio orientador para a limitação do poder estatal condicionado às regras jurídicas vigentes, como também é o principal elemento orientador das relações internas e internacionais. Ressalte-se que "o princípio da prevalência dos direitos humanos contribui substancialmente para o sucesso da ratificação, pelo Estado Brasileiro, de instrumentos internacionais de proteção aos direitos humanos" (PIOVESAN, 2008. p. 41).

A ratificação dos instrumentos internacionais pelo Brasil garante maior ênfase à proteção dos direitos humanos, como também aos direitos civis, políticos e sociais do indivíduo, tanto na esfera interna quanto na esfera internacional.

Insta salientar que, os direitos humanos são vistos como uma unidade indivisível que abrange um universo de garantias que antes eram velados à sociedade, dessa forma, se um dos direitos referidos forem violados, os demais também são.

A iniciativa de universalização dos direitos humanos abriu uma grande porta para a formação de um sistema internacional de proteção destes direitos, tidos como uma unidade universal e indivisível de direitos, garantidos de forma individual, o que impõe aos Estados, que ratificam esses tratados, a obrigação primordial ao resguardo dos direitos humanos e garantias fundamentais, sem ferir sua ordem política interna.

Segundo Kant (1993), o que caracteriza o ser humano e o torna investido de dignidade especial é o fato de que ele jamais pode ser visto como meio para outros fins, mas fim em si mesmo. Assim, se os constituintes entenderam que a dignidade da pessoa humana é fundamento da República Federativa do Brasil, estende-se essa compreensão na inclusão do Estado como existente em função de todas as pessoas, contrapondo-se às vencidas ideias de existência daquelas em função do Estado, como nos regimes totalitários.

Será inconstitucional qualquer ação do Estado que não contemple o respeito à dignidade da pessoa humana considerada como modelo avaliativo nas ações do Poder Público. Elegendo-se neste contexto, a concepção individualista é preciso ir além da tomada do homem como fim em si mesmo e da existência do Estado em sua função. Faz-se necessário promover a integração, a interrelação entre os valores individuais e coletivos.

Conforme Canotilho, citado por Fernando Ferreira Santos, (1999) "a pessoa é, nesta perspectiva, o valor último, o valor supremo da democracia, que 
a dimensiona e humaniza”.

Relembre-se, neste momento, a decisão do Tribunal Constitucional espanhol que, precisando justamente o significado da primazia da dignidade da pessoa humana (art. 10.1 da Constituição espanhola), sublinhou que a dignidade há de permanecer inalterável qualquer que seja a situação em que a pessoa se encontre, constituindo em conseqüência, um minimum invulnerável que todo estado jurídico deve assegurar (SANTOS , 1999, p. 7).

Assim, tendo a dignidade da pessoa humana como um princípio absoluto, ainda que se deva optar, em determinada circunstância, pelo valor destinado à sociedade, tal escolha não poderá aviltar, violar o valor da pessoa. Rejeitam-se desta feita, os princípios absolutos em detrimento dos individuais.

Dispõe o art. $5^{\circ}$, III, da Constituição Federal brasileira que "ninguém será submetido à tortura nem a tratamento desumano ou degradante", com especial coerência. Contempla esta previsão constitucional a integridade física e espiritual do homem como irrenunciável da sua individualidade autonomamente responsável, a garantia da identidade e integridade da pessoa através do livre desenvolvimento da personalidade bem como o trabalho e a garantia de existência digna., como obrigação negativa do Estado (SANTOS, 1999).

Por outro lado, a obrigação positiva ampara-se na liberdade de cada homem dispor de suas próprias capacidades, bem como a autodeterminação consequente da razão humana, ambas relativas ao desenvolvimento de cada pessoa.

Como essência dos direitos fundamentais está a dignidade da pessoa humana, fonte jurídico-positiva dos direitos fundamentais; a fonte ética que confere unidade de sentido, de valor e de concordância prática para realização dos direitos fundamentais (SANTOS, 1999).

Depreende-se desta análise, a compreensão de que ao serem interpretados os demais preceitos constitucionais e legais, será feito consubstanciada na proclamação dos direitos fundamentais.

\subsection{STATUS JURÍDICO ATRIBUÍDO AOS DIREITOS HUMANOS PELA CF DE 1988}

Diversas são as correntes que tratam da hierarquia dos tratados internacionais sobre direitos humanos no que se refere à sua recepção pelo ordenamento brasileiro, a saber: a)- a questão da hierarquia infraconstitucional; b)- a equivalência supralegal, porém infraconstitucional; c)- a equivalência constitucional; d) a supraconstitucionalidade dos tratados de direitos humanos.

Sobre a questão da hierarquia infraconstitucional, superando-se os en- 
tendimentos relativos à equivalência infraconstitucional bem como a decisão do STF de que os tratados internacionais estariam subordinados hierarquicamente à Constituição Federal, no que se refere aos tratados internacionais de direitos humanos, a Emenda Constitucional 45, trazendo o acréscimo do $\S 3^{\circ}$ no art. $5^{\circ}$ da Constituição Federal de 1988, elegeu a possibilidade de acolhimento destes documentos à Lei Maior com status de emenda constitucional, desde que cumprida a condição de tramitação legislativa com aprovação, em dois turnos por $3 / 5$ nas duas casas congressuais.

Restava assim, até 2006, o entendimento para os demais tratados internacionais e os tratados de direitos humanos cuja aprovação se desse por maioria simples, a opção de permanecerem como lei infraconstitucional, sendo que possíveis conflitos entre normas federais de mesmo nível, leis ordinárias e tratados internacionais não elevadas por emendas constitucionais, deveriam ser solucionados pela relação entre leis especial e geral.

A supralegalidade com caráter infraconstitucional manifesta uma oportuna e cômoda posição político-jurídica dos Estados. Se por um lado fortalece o que estabelece a Convenção de Viena de 1986, no que diz respeito ao cumprimento do que foi pactuado, princípio pacta sun servanda, por outro propicia o fortalecimento da soberania constitucional de cada Estado.

Se não há unanimidade entre os doutrinadores, sobre a recepção dos tratados internacionais no ordenamento pátrio entre nós, prevalece a ideia de que esses tratados devem ser recepcionados em status superior as leis federais, sejam eles tratados comuns ou de direitos humanos.

É importante frisar que a Constituição de 1988, demarca logo em seu artigo $1^{\circ}$, inciso III, a consagração do direito a dignidade da pessoa humana, que é elevado como princípio fundamental a orientar a interpretação do sistema constitucional.

Segundo Alexandre de Moraes, o princípio da dignidade da pessoa humana,

apresenta uma dupla concepção. Primeiramente, prevê um direito individual protetivo, seja em relação ao próprio Estado, seja em relação aos demais indivíduos. Em segundo lugar estabelece verdadeiro dever fundamental de tratamento igualitário dos próprios semelhantes" (MORAES, 2007, p. 46).

Com a instauração dos tratados internacionais em face do resguardo dos direitos humanos, a Constituição de 1988 inovou seu livro trazendo em seu art. $5^{\circ}, \S 2^{\circ}$ a interação entre o direito brasileiro e os tratados internacionais que asseguram a efetivação dos direitos humanos no plano internacional e interno. 
O referido artigo estabelece em seu texto que "os direitos e garantias expressos nesta constituição não excluem outros decorrentes do regime e dos princípios por ela adotados, ou os tratados internacionais em que a República Federativa do Brasil seja parte" (BRASIL, 1988). Ou seja, não poderão ser excluídos os direitos e garantias de caráter constitucional, desde que expressamente previstos em seu texto.

Os princípios constitucionais assegurados no art. $5^{\circ}, \S 2^{\circ}$ decorrentes de tratados internacionais passam a ter valor de norma constitucional, portanto, deve ser atribuída em sua interpretação a máxima efetividade da norma, não podendo no momento de sua aplicação diminuir ou retirar sua real razão de ser, principalmente quando se tratar de normas que assegurem direitos e garantias fundamentais.

Expressa José Joaquim Gomes Canotilho, que o princípio da máxima efetividade das normas constitucionais "é hoje, sobretudo invocado no âmbito dos direitos fundamentais - no caso de dúvidas deve preferir-se a interpretação que reconheça maior eficácia aos direitos fundamentais" (CANOTILHO, 1998, p. 227). Desta forma, estende-se aos direitos enunciados no tratado internacional, o regime constitucional que é conferido aos demais direitos e garantias fundamentais.

No mesmo sentido ensina Flávia Piovesan:

A Constituição de 1988 recepciona os direitos enunciados em tratados internacionais de que o Brasil é parte, conferindo-lhes natureza de norma constitucional. Isto é, os direitos constantes nos tratados internacionais integram e complementam o catálogo de direitos constitucionalmente previsto, o que justifica entender a esses direitos o regime constitucional conferido aos demais direitos e garantias constitucionais (PIOVESAN, 2008, p. 58).

Assim, a Constituição reconhece a relevância da proteção internacional para o âmbito interno e admite a natureza constitucional dos direitos ratificados por tratados internacionais em que Brasil seja parte.

É importante ressaltar, que os direitos constantes dos tratados internacionais e os demais direitos e garantias asseguradas pela Constituição de 1988, têm sua aplicação imediata no plano interno, tem status de cláusulas pétreas e não podem ser abolidos por eventuais emendas à Constituição, nos termos do art. $60, \S 4^{\circ}$ da CF/88.

A Emenda Constitucional $n^{\circ} 45$ de 2004, iniciou a chamada Reforma do Judiciário. Buscou o legislador tanto promover a celeridade processual como dar mais seriedade a matéria de direitos humanos, inserindo o $\S 3^{\circ}$ do art. $5^{\circ}$ da $\mathrm{CF} / 88$ cuja redação dispõe que "Os tratados e convenções internacionais sobre 
direitos humanos que forem aprovados, em cada Casa do Congresso Nacional, em dois turnos, por três quintos dos votos dos respectivos membros, serão equivalentes às emendas à Constituição".

Quando o tema lançado é de direitos humanos, o que se deve ser imperiosamente observado no ordenamento jurídico pátrio é o que primeiramente informa a Carta Magna, ou seja, o texto jurídico máximo, que no Brasil é a Constituição Federal de 1988.

Segundo lições de Mazzuoli (2010), o estudo deve ser feito de maneira conjugada, e no caso da proposta deste trabalho, devem ser observados os $\S \S 2^{\circ}$ e $3^{\circ}$ do art. $5^{\circ}$ da Constituição.

Para esse internacionalista, com o advento da Constituição de 1988, que representou o ponto fulcral na redemocratização do Brasil, que a propósito ainda está caminhando para uma verdadeira democracia, ocorreu o fenômeno da abertura do regime jurídico interno para recepção da nova ordem jurídica internacional no que afeta à tutela dos direitos humanos, mais especificamente no tema dos tratados (em sentido lato) internacionais de direito humanos, prova disso, é a constatação de ser o Brasil participante de quase a totalidade dos principais tratados internacionais de direito humanos, com a crescente ratificação desses tratados, tanto no sistema global (informado pelas Nações Unidas), quanto no sistema regional interamericano. Observa-se, desta forma, que a Constituição atual é flexível e não exauriente quanto ao tema dos direitos humanos.

Ocorre que, apesar dessa constatação de abertura constitucional à nova ordem internacional sobre direitos humanos, no âmbito interno, têm permanecido vivas as controvérsias quanto à natureza dos tratados que versem sobre $o$ direito humanitário, como já exposto. Isto é, as divergências ocorrem em torno da questão de qual patamar seriam aqueles tratados recebidos pelo ordenamento jurídico interno. As posições são diversas, como demonstrado. Existem os que defendem que esses tratados seriam internalizados no patamar de supraconstitucionalidade, outros militam no sentido de que seriam recebidos como normas supralegais, há ainda os que entendem que os tratados ingressariam com o status de lei ordinária, como é o posicionamento majoritário da Corte Suprema Brasileira e, por fim, a corrente que advoga a tese de que os tratados de direitos humanitários sempre deveriam ser internalizados com o status de norma constitucional.

Segundo Mazzuoli (2010), a Constituição trouxe nesse $\S 2^{\circ}$ uma outorga para ampliação do "bloco de constitucionalidade". O "bloco de constitucionalidade" seria toda a normatividade constitucional informada pelos seus princípios, implícitos ou expressos, normas positivadas formalmente em seu texto, como também as normas positivadas materialmente. Essa interpretação se faz consoante com o princípio da máxima efetividade das normas constitucionais.

Corroborando com esta tese, cabe consignar o que leciona Konrad Hes- 
se:

A interpretação tem significado decisivo para a consolidação e preservação da força normativa da Constituição. A interpretação constitucional está submetida ao princípio da ótima concretização da norma. (...) A interpretação adequada é aquela que consegue concretizar, de forma excelente, o sentido da proposição normativa dentro das condições reais dominantes numa determinada situação. A dinâmica existente na interpretação construtiva constitui condição fundamental da força normativa da Constituição e, por conseguinte, de estabilidade. Caso ela venha a faltar, tornar-se-á inevitável, cedo ou tarde, a ruptura da situação jurídica vigente (HESSE, 1991, p. 22-23).

$\mathrm{O}$ ponto principal que permite tal interpretação, segundo Valério Mazzuoli, está quando o dispositivo Constitucional dispõe:

[...] que os direitos e garantias nele elencados "não excluem" outros provenientes dos tratados internacionais em que a República Federativa do Brasil seja parte, é porque ele própria está a autorizar que esses direitos e garantias internacionais constantes dos tratados internacionais de direitos humanos ratificados pelo Brasil "se incluem" no nosso ordenamento jurídico interno, passando a ser considerados como se escritos na Constituição estivessem (MAZZUOLI, 2010, p. $750)$.

De acordo com o nobre doutrinador, do $\S 2^{\circ}$ do art. $5^{\circ}$ emanam duas fontes normativas, uma no âmbito nacional interno, que são os "direitos expressos", que são os positivados formalmente, e os "direitos implícitos", com fulcro no regime e princípios constitucionais; e outra que vem a ser emanada de âmbito externo, do direito internacional, que justamente seriam aquelas oriundas do direito convencional, isto é, dos tratados (lato senso).

Dessa forma, o próprio constituinte deixou está “cláusula aberta" para que outros direitos e garantias fundamentais, como é o direito humanitário, pudessem complementar, através dos tratados o rol, repita-se, não taxativo e exauriente, do art. $5^{\circ}$, da Constituição, bem como, de todo a normatividade constitucional esparsa. Estando, então, os tratados internacionais de direitos humanos legitimados à ingressarem no ordenamento jurídico interno com o status de norma constitucional, como deixa entrever o próprio texto maior.

Mas apesar desta evidente constatação, a famigerada discussão, em torno do nível em que deveriam ser internalizados aqueles tratados, existe, e para tentar contornar a situação, o constituinte derivado com a edição da Emenda Constitucional de $\mathrm{n}^{\circ} 45$ de 2004, conhecida como Reforma do Judiciário, inseriu no art. $5^{\circ}$ da Constituição o $\S 3^{\circ}$, em termos semelhantes ao do art. $60, \S 2^{\circ}, \mathrm{CF}$, 
que trata do processo de Emenda à Constituição. In verbis:

$\S 3^{\circ}$ Os tratados e convenções internacionais sobre direitos humanos que forem aprovados, em cada Casa do Congresso Nacional, em dois turnos, por três quintos dos votos dos respectivos membros, serão equivalentes às emendas constitucionais.

Mas o que se põe em xeque sobre o parágrafo inserido no artigo $5^{\circ}$ da Constituição, ou seja, o $\S 3^{\circ}$, é a indagação de que se realmente essa inserção e "alteração" no texto Constitucional trouxe benesses, como por exemplo, o fim das divergências acerca do nível em que seriam recebidos os tratados internacionais de direitos humanos no ordenamento pátrio, que ora é exposto neste trabalho.

O que se observa, é que conforme ensina Mazzuoli (2010), o novo parágrafo ao invés de trazer pacificação, trouxe algumas "incongruências". E para isso alerta que um Estado passa a estar vinculado a um tratado internacional a partir do momento de sua ratificação, independente da forma da processualística interna. Seriam os tratados de direitos humanos regidos pelos princípios do direito internacional público, principalmente aquelas novas fontes do direito internacional, chamadas de jus cogens, que inclusive encontra respaldo na Convenção de Viena de 69, e que encontra consenso no âmbito internacional. Tem-se como exemplo, a proibição de tratados que "permita o genocídio, o tráfico de escravos, a guerra de agressão, a tortura ou a pirataria", Mazzuoli (2010, p. 135), como também, a discriminação racial e a reafirmação da autodeterminação dos povos. Seria então, o jus cogens uma normatividade de natureza de ordem pública.

Observa-se que, desta forma, o tratado de direitos humanos não dependeria individualmente do ordenamento nacional de qualquer Estado para que se aferisse a elevada importância do seu conteúdo material, e sendo assim, o $\S 3^{\circ}$ causa um certo "desvirtuamento" do $\S 2^{\circ}$ do mesmo artigo constitucional, pois o constituinte originário já houvera estabelecido este como "cláusula aberta" à recepção de tratados de direitos humanos em nível materialmente constitucionais, não havendo razão de ser a criação de mandamento de algo que já estaria patente em texto já existente.

Parece que houve certo preciosismo legislativo, podendo gerar futuras "incongruências", em relação a uma possível hierarquização de tratados que tem como tema central direitos humanos, pois pode ocorrer que tratados que não passem por uma processualística nos moldes do $\S 3^{\circ}$, do art. $5^{\circ}$, fiquem com a sua valoração prejudicada formalmente em face daqueles que forem submetidos ao referendum do rito especial em tela.

Portanto, observa-se que, desconsiderando o $\S 2^{\circ}$, que com a inserção 
do $\S 3^{\circ}$, apenas os tratados submetidos ao quorum especial teriam o status constitucional. Mas que teriam sim, um status constitucional, e desta feita um status formalmente constitucional, pois o status material, sempre possuiu em virtude da "cláusula aberta".

Nesta mesma linha intelectiva, pondera Flávia Piovesan, in verbis:

Vale dizer, com o advento do $\S 3^{\circ}$ do art. $5^{\circ}$ surgem duas categorias de tratados internacionais de proteção de direitos humanos: a) os materialmente constitucionais; e b) os material e formalmente constitucionais. Frise-se: todos os tratados internacionais de direitos humanos são materialmente constitucionais, pro força do $\S 2^{\circ}$ do art. $5^{\circ}$. Para além de serem materialmente constitucionais, poderão, a partir do $\S$ $3^{\circ}$ do mesmo dispositivo, acrescer a qualidade de formalmente constitucionais, equiparando-se às emendas à Constituição, no âmbito formal (PIOVESAN, 2010, p. 79).

Outra questão que pode se levantada é de como ficariam os tratados anteriores? Ficariam com o status da posição majoritária do STF, de que teriam o status de lei ordinária? Haveria, então, uma "categorização" entre os tratados de direitos humanos?

Ora, como solução a esses questionamentos, fundado em posição que defende o status sempre constitucional dos tratados de direitos humanos, ainda que materialmente, seria a aceitação majoritária da doutrina e jurisprudência em vislumbrar o $\S 2^{\circ}$, como realmente uma "cláusula aberta", fazendo-se uma interpretação teleológica, considerando todo o arcabouço constitucional e os direitos humanos como realmente especiais no ordenamento interno, sem deixar azo para dúvidas acerca de sua validade e legitimidade.

Outras questões que se observam com o $\S 3^{\circ}$, são de que este possui um rito processual legislativo diverso do rito adotado para os tratados internacionais comuns, pois para estes é adotado um rito que exige a maioria simples, de acordo com o art. 47 da Constituição, e para os tratados de direitos humanos fica a cargo de decisão do Congresso, observando a regra do art. 49, I, da CF, no entanto terá o Congresso a discricionariedade em decidir por qual rito pretende passar determinado tratado de direitos humanos, isto é, poderá optar em seguir o rito dos tratados comuns ou o rito especial do $\S 3^{\circ}$, que exige um quorum qualificado de três quintos.

Mas qual será a consequência lógica para em um ou outro rito? A consequência é que se o Congresso optar em referendar um tratado de direitos humanos passando pelo rito do $\S 3^{\circ}$, este adquirirá o status constitucional de maneira formal, ao passo que, se optar em referendar pelo rito antigo do art. 47, que ainda continua em vigor, o tratado não adquirirá o status formalmente constitucional, 
ficando a cargo da doutrina e jurisprudência decidirem o real nível em que será internalizado, ressalvando que para os que defendem uma interpretação teleológica do $\S 2^{\circ}$, o tratado independente do rito terá o status constitucional.

Desta forma, com observações da doutrina, a processualística do $\S 3^{\circ}$ é semelhante àquela adotada para as Emendas Constitucionais, mas o parágrafo não determina que se deva seguir o rito das emendas, qual seja a do art. 60, da Constituição Federal. Isso explica a abertura discricionária que a inovação do constituinte derivado trouxe para baila da internalização dos tratados humanitários.

E como consequências principais, além de não ter sanado as vivas discussões em torno do status daqueles tratados no ordenamento pátrio, a mudança trouxe insegurança jurídica, pois poderá causar uma eventual "hierarquização" de tratados de mesma natureza jurídica, qual seja a humanitária, gerando confusão e incertezas no momento de escolha, no caso concreto. A questão é saber qual norma prevalecerá em detrimento de outra, tendo ambas a mesma natureza, podendo ocorrer que uma norma constitucional mais benéfica sofra detrimento com a eventual prevalência de um tratado menos benéfico.

$\mathrm{O}$ entendimento é de que fere princípios internacionais de direitos humanos, como o princípio da primazia da norma mais favorável (pro homine) reconhecidos na maioria dos textos constitucionais alienígenas, que na moderna ordem internacional, regidos preponderantemente pelo "direito das gentes", principalmente após as grandes guerras mundiais, têm elevado a mais alta categoria a tutela e a internalização dos direitos humanos nos ordenamentos jurídicos internos. Ocorre que, conforme assevera Valério Mazzuoli, o poder reformador brasileiro perdeu uma grande chance de dar primazia aos tratados internacionais de direitos humanos, in verbis:

Tais textos constitucionais latino-americanos são, portanto, reflexo do constitucionalismo que vem se desenvolvendo em todos os países democráticos do mundo. O Brasil, segundo pensamos, ficou atrasado em relação aos demais países da América Latina, em relação à eficácia interna dos tratados internacionais de proteção dos direitos humanos,não obstante ter tido a oportunidade de rever alguns dos conceitos equivocados que a jurisprudência atual veio sedimentando através dos tempos, quando promulgou a Emenda Constitucional nº 45/2004 (MAZZUOLI, 2010, p. 780).

Outras diferenças que se podem notar com o advento do $\S 3^{\circ}$, é o que ocorre com a questão da eficácia, pois se outrora, com o $\S 2^{\circ}$, os tratados de direitos humanos possuíam eficácia material constitucional, ou seja, status constitucional. $\mathrm{O} \S 3^{\circ}$ possibilita a eficácia formal constitucional, equivalente a emenda 
constitucional, de operacionalidade mais ampla do que antes, pois dois efeitos principais são extraídos: o primeiro é o poder de reformar a Constituição e o segundo e o de não ser possível a sua denuncia unilateral, como pode ocorrer caso o legislador opte em seguir o rito comum do art. 47. Andou bem o constituinte derivado neste ponto, proporcionando uma limitação ao poder discricionário do Chefe do Executivo, sob pena de haver sua responsabilização, quanto a um tema tão importante, que é o de direitos humanos. Quanto ao primeiro efeito, tem o tratado o poder de formalmente alterar o texto maior nacional, tornando inconstitucional todos a normatividade que lhe contrarie, pois agora tem a semelhança de emenda constitucional e eficácia de norma constitucional.

Finalmente, após a exposição de algumas alterações que trouxe o $\S$ $3^{\circ}$, parece ser irrelevante, conforme posição de doutrina que defende a quarta das teses alhures mencionadas, a de status constitucional, a discussão acerca do momento da ratificação do tratado. Com fundamento no $\S 2^{\circ}$, os tratados de direitos humanos sempre detiveram o status de norma constitucional, frente a todo arcabouço constitucional, principalmente quando informa seus princípios e fundamentos, como aqueles do artigo $4^{\circ}$, inciso II, a prevalência dos direitos humanos nas relações internacionais, além dos incisos III e VIII do mesmo artigo. Princípios do Direito Internacional dos Direitos Humanos, quais sejam, a autodeterminação dos povos e não discriminação racial e o fundamento principal humanitário, a dignidade da pessoa humana.

Ademais, os tratados de direitos humanos têm aplicação imediata, com fundamento no $\S 1^{\circ}$, art. $5^{\circ}$, da CF, isto é, não devem depender de aplicação do $\S$ $3^{\circ}$, pois ao determinar que as normas dos direitos e garantias fundamentais têm aplicação imediata, está assim autorizando o cumprimento dos direitos humanos, ainda que materialmente constitucionais, pois como se sabe direitos e garantias fundamentais são parte de direitos humanos e não se pode tutelar a parte sem o todo, sob o risco de incorrer em subversão e insegurança jurídica.

\section{CONSIDERAÇÕES FINAIS}

Em conexão com a síntese exposta, observa-se que em linhas gerais, na doutrina e jurisprudência interna, quando o tema é afeto à posição, status, em que devem ocupar os tratados internacionais de direitos humanos de que o Brasil seja parte, já houve e ainda há divergências acerca do seu nível hierárquico no ordenamento jurídico pátrio.

Conclui-se que com o advento da conhecida "reforma do judiciário", que com a Emenda Constitucional $n^{\circ}$. 45/2004, inseriu o $\S 3^{\circ}$ ao artigo $5^{\circ}$, da Constituição da República Federativa do Brasil, parece não ter obtido o êxito que se esperava, pois não trouxe uma pacificação ideal sobre o tema, visto que, 
ao revés, trouxe algumas incongruências em face de outros dispositivos constitucionais do mesmo artigo $5^{\circ}$, sobretudo em relação ao $\S 2^{\circ}$ e possíveis anomalias na aplicação ao caso concreto de determinado tratado de direitos humanos em detrimento de outro de igual natureza, gerando insegurança jurídica.

Assim, infere-se que ainda não é uníssono, na doutrina e jurisprudência, uma interpretação sistemática e teleológica, no que se refere à "posição hierárquica" que devem ocupar os tratados de direitos humanos no ordenamento jurídico pátrio.

\section{REFERÊNCIAS}

ALVES, C. F. O princípio constitucional da dignidade da pessoa humana: o enfoque da doutrina social da igreja. Rio de Janeiro: Renovar, 2001.

ARISTÓTELES. A política. São Paulo: M. Fontes, 2000.

BEVILAQUA, C. Teoria geral do direito civil. Campinas: Servanda, 2007.

BONAVIDES, P. Curso de direito constitucional. 10. ed. São Paulo: Malheiros, 2000.

BRASIL. Constituição (1988). Constituição da República Federativa do Brasil de 1988. São Paulo: Saraiva, 2008.

CANOTILHO, J. J. Direito constitucional e teoria da Constituição. Coimbra: Almedina, 1998.

COMPARATO, F. K. A afirmação histórica dos direitos humanos. São Paulo: Saraiva, 1999.

DIMOULIS, D.; MARTINS, L. Teoria dos direitos fundamentais. São Paulo: Revista dos Tribunais, 2007.

GUERRA, S. Curso de direito internacional público. 7. ed. São Paulo: Saraiva, 2013.

HESSE, K. A força normativa da Constituição. Tradução Gilmar Ferreira Mendes. Porto Alegre: S. A. Fabris, 1991.

KANT, I. Crítica da razão pura. São Paulo: Abril, 1993. (Coleção os Pensadores). 
MATA-MACHADO, E. de G. Contribuição ao personalismo jurídico. Belo Horizonte: Del Rey, 1991.

MAZZUOLI, V. de O. Curso de direito internacional. 3. ed. São Paulo: Revista dos Tribunais, 2010.

MORAES, A. Direitos humanos fundamentais. São Paulo: Atlas, 2002.

. Direitos humanos fundamentais: teoria geral. São Paulo: Atlas, 2007.

REALE, M. Questões de direito público. In: SANTOS, F. F. Princípio constitucional da pessoa humana. Fortaleza: C. Bastos, 1999.

SANTOS, F. F. dos. Princípio constitucional da pessoa humana. Fortaleza: C. Bastos, 1999.

PIOVESAN, F. Temas de direitos humanos. 3. ed. São Paulo: Max Limonad, 2008.

2008.

. Direitos humanos e justiça internacional. 2. ed. São Paulo: Saraiva,

. Direitos humanos e o direito constitucional internacional. 11. ed.

São Paulo: Saraiva, 2010.

VILLAS-BOAS, R. M. Homem, pessoa e personalidade: parte I. Revista Prática Jurídica, n. 125, 31 ago. 2012.

\title{
HUMAN RIGHTS: INTEGRATION AND COMPLEMENTATION OF NORMATIVE DEVICES IN THE BRAZILIAN LAW
}

\begin{abstract}
The present work has the purpose of introducing the importance of the protection of human rights both in the internal market and in the international sphere; the historical evolution of human rights having as scope the fundamental value of human dignity as one of the guiding principles of the legal system that has contributed to the process of internationalization of human rights. Also, demonstrate the reception given to human rights by the 1988 Federal Constitution that enabled the process of democratization in Brazil, breaking the conception of state absolute sovereignty and recognizing the existence of limits to the powers of the State. It also tries to analyze the interaction between the internal legal system and the international human rights law along with the inno-
\end{abstract}


vations brought by the Constitutional Amendment no. 45 of 2004, which started what is called the "Reform of the Judiciary", with the objective of clarifying and producing greater legal security, inserting $\S 3$ to Article 5 in the Constitution of the Federative Republic of Brazil.

KEYWORDS: Human rights; Principles; Limits; Power; Legal security.

\section{DERECHOS HUMANOS: INTEGRACIÓN Y COMPLEMENTACIÓN DE LOS DISPOSITIVOS NORMATIVOS DEL DERECHO BRASILEÑO}

RESUMEN: Este trabajo ha tenido como finalidad presentar la importancia de la protección de los derechos humanos, tanto en el ámbito interno como en el ámbito internacional; la evolución histórica de los derechos humanos, teniendo como objetivo fundamental el valor de la dignidad humana, como uno de los principios orientadores del ordenamiento jurídico que contribuyó para el proceso de internacionalización de los derechos humanos. Demostrar la recepción dada a los derechos humanos por la Constitución Federal de 1988 en el cual dio lugar el proceso de redemocratización de Brasil, rompiendo la concepción de soberanía estatal absoluta y reconoce la existencia de límites al poder del Estado. Se ha buscado también, analizar la interacción entre el sistema jurídico interno y el derecho internacional de derechos humanos, juntamente con las innovaciones traídas por la Emenda Constitucional n 45 de 2004 que inició la llamada "Reforma del Poder Judiciario", objetivando aclarar y producir mayor seguridad jurídica, insiriendo el $\S 3^{\circ}$, al artículo $5^{\circ}$ de la Constitución de la República Federativa de Brasil.

PALABRAS CLAVE: Derechos humanos; Principios; Límites; Poder; Seguridad jurídica. 